\title{
Occurrences of pharmaceuticals in drinking water sources of major river watersheds, China
}

\author{
Jing Sun ${ }^{\mathrm{a}}$, Qian Luo ${ }^{\mathrm{a}, \mathrm{b}, *}$, Donghong Wang ${ }^{\mathrm{a}}$, Zijian Wang ${ }^{\mathrm{a}, * * *}$ \\ a State Key Laboratory of Environmental Aquatic Chemistry, Research Center for Eco-Environmental Sciences, Chinese Academy of Sciences, Beijing 100085, \\ $P R$, China \\ b Shenzhen Institutes of Advanced Technology, Chinese Academy of Sciences, Shenzhen 518055, China
}

\section{A R T I C L E I N F O}

\section{Article history:}

Received 26 September 2014

Received in revised form

26 March 2015

Accepted 27 March 2015

Available online 5 April 2015

\section{Keywords:}

Pharmaceutical

Drinking water

Occurrence in China

Causality analysis

\begin{abstract}
A B S T R A C T
Pharmaceuticals in drinking water sources (DWSs) have raised significant concerns for their persistent input and potential human health risks. Currently, little is known about the occurrence of pharmaceuticals in DWSs in China. In this study, a survey for multi-class pharmaceuticals in DWSs of five major river watersheds in China was conducted from 2012 to 2013. Samples were collected from 25 sampling sites in rivers and reservoirs. 135 pharmaceuticals were analyzed using solid-phase extraction and ultra-performance liquid chromatography tandem mass spectrometry. The results showed that a total of 70 pharmaceuticals were present in the samples, and the most frequently detected ones included sulfonamides, macrolides, antiepileptic drugs, anti-inflammatory drugs, and $\beta$-blockers, etc. Amongst these, maximum concentrations of lincomycin, sulfamethoxazole, acetaminophen and paraxanthine were between $44 \mathrm{ng} / \mathrm{L}$ and $134 \mathrm{ng} / \mathrm{L}$, and those of metoprolol, diphenhydramine, venlafaxine, nalidixic acid and androstenedione were less than $1 \mathrm{ng} / \mathrm{L}$. Concentrations of the two that were most persistent, DEET and carbamazepine, were $0.8-10.2 \mathrm{ng} / \mathrm{L}$ and $0.01-3.5 \mathrm{ng} / \mathrm{L}$, respectively. Higher concentrations of cotinine were observed in warm season than in cold season, while concentrations of lincomycin were the opposite. In a causality analysis, the occurrence of pharmaceuticals in DWSs depends mainly on the detection limits of the methods, their usage and the persistence in the aquatic environment.
\end{abstract}

(c) 2015 Elsevier Inc. All rights reserved.

\section{Introduction}

Pharmaceuticals are so-called "pseudo-persistent" contaminants in aquatic environments because of their consistent consumption, and their polar and non-volatile properties (Daughton, 2003). Pharmaceuticals include diverse groups, such as antibiotics, antiepileptics, non-steroidal anti-inflammatory drug (NSAIDs), blood-lipid regulators, antihistamines, $\beta$-blockers, antiulcer agents, anti-asthma drugs, serotonin re-uptake inhibitors and steroidal hormones. These compounds, together with their

\footnotetext{
Abbreviations: DEET, diethyltoluamide; DWS, drinking water source; GPS, global positioning system; MDL, method detection limit; MQL, method quantification limit; NSAID, non-steroidal anti-inflammatory drug; U.S., United States; MRM, multiple reactions monitoring

* Corresponding author at: Shenzhen Institutes of Advanced Technology, Chinese Academy of Sciences, Shenzhen 518055, China. Tel.: + 8675586585330 ; fax: +8675586585247

** Corresponding author at: State Key Laboratory of Environmental Aquatic Chemistry, Research Center for Eco-Environmental Sciences, Chinese Academy of Sciences, Beijing 100085, China. Tel./fax: +861062849140.

E-mail addresses: qian.luo@siat.ac.cn (Q. Luo), wangzj@rcees.ac.cn (Z. Wang).
}

metabolites/transformation products, primarily enter aquatic environments via the effluents of municipal wastewater treatment plants (Nikolaou et al., 2007), discharges of sewage sludge (Li et al., 2013), livestock waste (Luo et al., 2011), and aquaculture activities (Zou et al., 2011). In receiving waters, certain pharmaceuticals, such as carbamazepine and diethyltoluamide (DEET), are resistant to natural degradation or transformation processes, resulting in their detection in rivers (de Jongh et al., 2012; Kolpin et al., 2002), lakes (Kleywegt et al., 2011) and reservoirs (Kim et al., 2007). The concentrations of detected pharmaceuticals normally occur at the ng/L level, but the concentrations of several pharmaceuticals, such as acetaminophen, caffeine and its metabolite paraxanthine, can exceed $1 \mu \mathrm{g} / \mathrm{L}$ (Kolpin et al., 2002). Due to the bio-activity of vast majority of pharmaceuticals, they could cause long-term adverse impacts to the aquatic organisms even at very low concentrations (Fent et al., 2006).

Drinking water sources (DWSs) are of great importance to human health. Multiple-classes of pharmaceuticals have been detected in DWSs in countries such as the United States (U.S.) (Benotti et al., 2009; Focazio et al., 2008), Canada (Kleywegt et al., 2011) and several European countries (de Jongh et al., 2012; Kuch 
and Ballschmiter, 2001; Mompelat et al., 2011; Valcárcel et al., 2013; Vulliet et al., 2011). In a national survey performed by the U.S. Geological Survey, several classes of pharmaceuticals, including antibiotics, prescription drugs, non-prescription drugs and other wastewater-related drugs, were detectable (Focazio et al., 2008), and the maximum concentrations of the detected pharmaceuticals ranged from $0.019 \mu \mathrm{g} / \mathrm{L}$ to $0.30 \mu \mathrm{g} / \mathrm{L}$. Not all pharmaceuticals are completely removed during drinking-water treatment processes (Benotti et al., 2009; Huerta-Fontela et al., 2011; Stackelberg et al., 2007; Vulliet et al., 2011). As a result, several pharmaceuticals, such as carbamazepine, lincomycin, ibuprofen, acetaminophen, erythromycin, roxithromycin and metoprolol, are also detectable in distribution waters (Delgado et al., 2012; Stackelberg et al., 2004; Vulliet et al., 2011). In Germany, ethinylestradiol, the active ingredient in oral contraceptive pills, was detected in four out of 10 distribution water samples at the $0.15-$ $0.50 \mathrm{ng} / \mathrm{L}$ level (Kuch and Ballschmiter, 2001). Ethinylestradiol may cause long-term endocrine disruption effects even at very low ng/L concentrations in distribution water (Vosges et al., 2008). The presence of various classes of pharmaceuticals in water may negatively affect the quality of drinking water and pose risks to human beings.

According to the Chinese Medical Statistical Yearbook 20062007, the domestic production of pharmaceuticals was $1,011,361 \mathrm{t}$ in 2006 (Fig. S1). The production of pharmaceuticals accounts for more than $20 \%$ of the global volume and increases annually (Liu and Wong, 2013). Two categories, i.e. antibiotics (93,375 t in 2006) and analgesics/antipyretics (84,371 $\mathrm{t}$ in 2006), are associated with relatively high production volumes in China, and the production volumes of several classes of pharmaceuticals, such as alimentary system agents, nervous system agents, antiparasitics and disinfectants, and urinary system drugs, exceed 5000 t (Fig. S1). Hence, multiple classes of pharmaceuticals in addition to antibiotics and analgesics/antipyretics should be considered in surveys of DWSs. According to recent reviews of pharmaceutical contamination in China (Bu et al., 2013; Liu and Wong, 2013), a few categories of pharmaceuticals (mainly antibiotics and hormones) and a limited number of sampling sites in specific geographical areas have been considered. The occurrences of multi-class pharmaceuticals in the DWSs of the major river watersheds in China have not been well documented.

To determine the levels of pharmaceuticals in DWSs, reliable and stable analytical methods with low detection limits are required. Recently, our research group developed an analytical method to determine multiple-classes of pharmaceuticals with method detection limits (MDLs) between $0.004 \mathrm{ng} / \mathrm{L}$ and $7 \mathrm{ng} / \mathrm{L}$ in drinking water samples. With this method, many substances presented in water could be detected due to the very low detection limits, especially in the case of the sulfonamides, most of the quinolones, most of the macrolides, most of the androgens, an antiulcer agent, anti-asthma drug, analgesic drug, antihistamine, a caffeine metabolite, a nicotine metabolite, a lipid regulating agent, a calcium channel blocker, $\beta$-blockers, tranquilizers and a lincosamide. The MDLs of these compounds were below $0.15 \mathrm{ng} / \mathrm{L}$. In the present survey, the method was applied for the priority list of candidate contaminants in DWSs located across five major river watersheds in China. The targeted pharmaceuticals were selected based on their production and consumption volumes in China, on their ubiquity and frequent detection in aquatic environments, as reported in the literature, and on their potential ecological impacts. The results reported in this paper will also enable international comparisons.

\section{Materials and methods}

\subsection{Chemicals and materials}

The targets were categorized into different groups, including antibiotics (sulfonamides, quinolones, tetracyclines, macrolides, a lincosamide and others), hormones (estrogens, progestogens, androgens and corticoids), anti-inflammatory drugs, $\beta$-blockers, antiulcer agents, receptor stimulants, analgesic drugs, antihistamines, serotonin re-uptake inhibitors, antiepileptics, tranquilizers, a lipid-regulating agent and a calcium channel blocker. In addition, two metabolites, i.e., cotinine and paraxanthine, one antifungal and two antimicrobials were also included.

\subsection{Sampling collection}

Brown glass bottles were used for sampling. To avoid contamination, all of the glassware used in the experiment was cleaned by being washed with detergent, rinsing with deionized water, and being heated at $110{ }^{\circ} \mathrm{C}$ for at least $2 \mathrm{~h}$. Glass-fiber filters were heated at $450{ }^{\circ} \mathrm{C}$ for $2 \mathrm{~h}$ before use.

Samples were taken from stations of five major river watersheds, namely, those of the Yangtze River (S1-S5), the Huai River (S6-S9), the Yellow River (S10-S14), the Hai River (S15-S19) and the Liao River (S20-S25), which represented the most important watersheds in China (Table S1). A total of two sampling campaigns were conducted, one in 2012 and the other in 2013. The sampling campaigns for both the Huai River and the Yellow River watersheds were conducted during the cold seasons (fall and winter) of 2012 and the warm season (summer) of 2013, respectively. The surveys in the Liao River were conducted during the summer of both years. The surveys in the Hai River watershed were sampled during the fall of both years. The sampling campaigns for the Yangtze watershed were conducted during the winter of 2012 and fall of 2013. A total of 25 sampling sites were selected, based on the information provided by the Ministry of Water Resources of the People's Republic of China (Fig. 1), from the most important DWSs in these river watersheds, consisting of a total of 13 reservoirs and 12 rivers that serve as the source waters for local drinking water systems for populations ranging from 0.8 million to 23 million individuals. All of the sampling sites were located within close proximity to municipal drinking water treatment plants, with varying land uses in the surrounding watersheds (i.e., cropland, forest and urban area). Most river-water locations were surrounded by land used for residential or cropland purpose, and most reservoir-water locations were located in well-preserved surroundings. One sample was collected for each site during the 2012 sampling campaign. Two samples were collected for each site during the 2013 sampling campaign (Table S1). A global positioning system (GPS) was used to locate the sampling sites (GPS locations are given in Table S1). Water quality parameters were measured in situ (Table S2). The total organic carbon concentrations of the water samples were analyzed in laboratory (Teledyne Tekmar, Mason, OH, U.S.) (Table S2).

\subsection{Sample extraction and instrumental analysis}

The water samples were transported to the laboratory in a cool condition (with ice) and stored under a cool condition $\left(4^{\circ} \mathrm{C}\right.$ ) within three days. Sample volumes were $2 \mathrm{~L}$. The water samples were filtered through $0.7 \mu \mathrm{m}$ glass-fiber filters. The filtered water samples were extracted by solid-phase extraction (SPE) with tandem cartridges: Oasis WAX (150 mg; $6 \mathrm{~mL}$ ) weak anion exchange mixed-mode cartridge coupled with Oasis HLB (500 mg; $6 \mathrm{~mL}$ ) hydrophilic-lipophilic balance cartridges. Before extraction, the samples were added with $\mathrm{Na}_{2} \mathrm{EDTA}$, adjusted to $\mathrm{pH} 6$. All the 


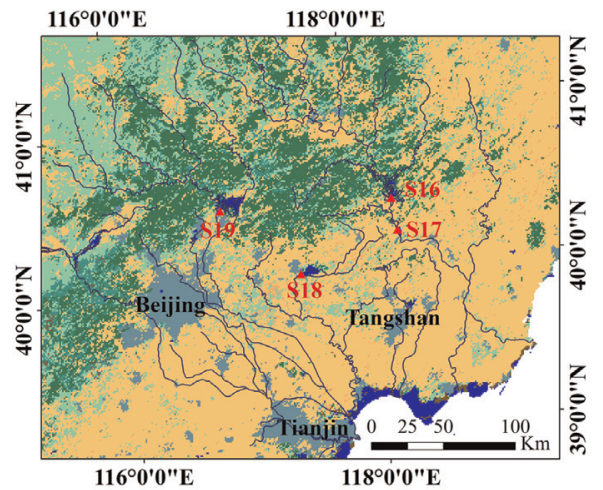

Hai River

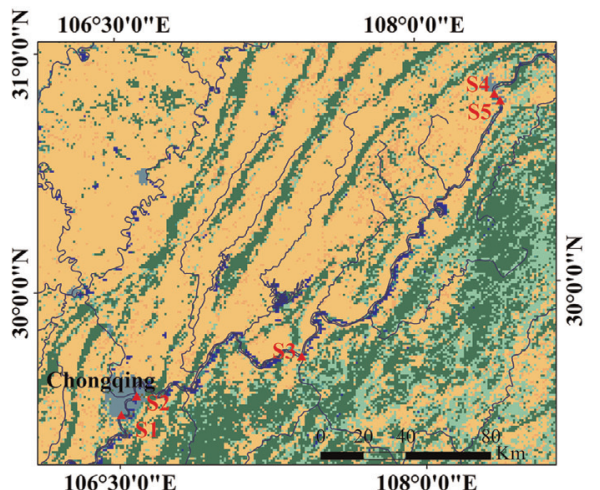

Yangtze River

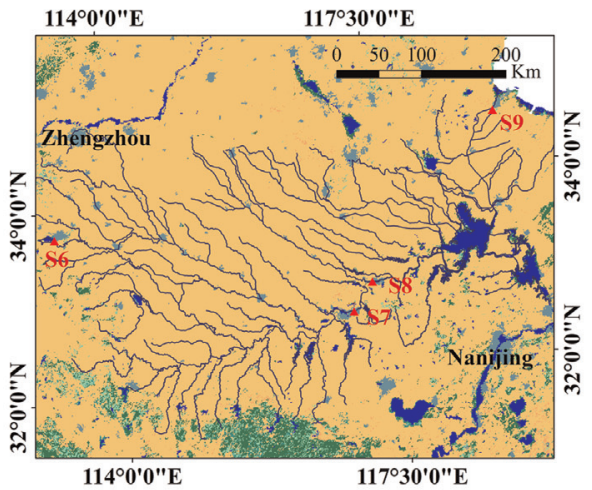

Huai River

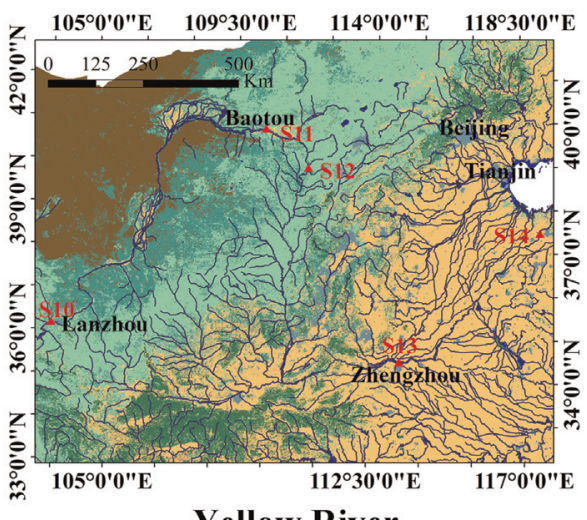

Yellow River

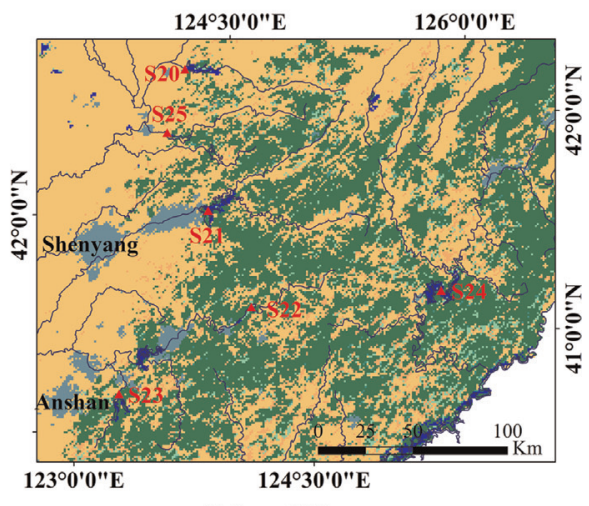

Liao River

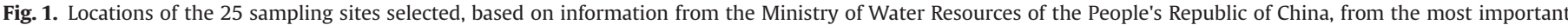

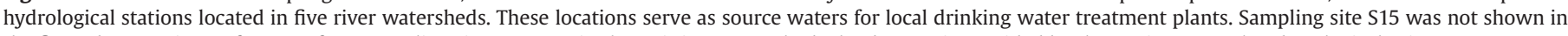

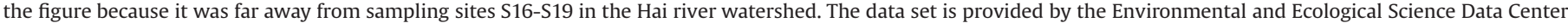
for West China, National Natural Science Foundation of China (http://westdc.westgis.ac.cn).

cartridges were activated and conditioned with $6 \mathrm{~mL}$ methanol and $6 \mathrm{~mL}$ ultrapure water. The water samples were passed through the tandem cartridges at a flow rate of $5 \mathrm{~mL} / \mathrm{min}$. After extraction, the columns were separated, rinsed with $6 \mathrm{~mL}$ water, and the cartridges dried for $30 \mathrm{~min}$. Elution was performed with 6-8 mL $1 \%(\mathrm{v} / \mathrm{v})$ ammonia in methanol (WAX cartridge) or $2 \%(\mathrm{v} / \mathrm{v})$ formic acid in methanol (HLB cartridge), 6-8 mL methanol-MTBE $(1 / 9, \mathrm{v} /$ v) and 6-8 mL methanol-dichloromethane $(2 / 8, v / v)$ for both WAX and HLB cartridges. The elution fractions from WAX and HLB cartridges were gathered. Evaporation of the extracts with nitrogen to $200 \mu \mathrm{L}$ was performed at a temperature of $40{ }^{\circ} \mathrm{C}$ in a water bath. The overall enrichment factor was 2000. All concentrates were filtered through a $0.2 \mu \mathrm{m}$ GHP membrane filter before analysis.

An ultra-performance liquid chromatography (UPLC) system coupled to a Micromass Quattro Premier XE tandem quadruple mass spectrometer with an electrospray ion source were used (Waters Corporation, Milford, MA, USA). The mass spectrometry system was operated for quantification of the targets in multiple reactions monitoring (MRM) acquisition mode with both positive and negative electrospray ionization. Identification was provided by the acquisition of two MRM transitions per compound in most cases (Table S3). The protonated or deprotonated molecular ion was chosen as the precursor ion for most analytes. For cortisones which were operated in negative mode, $\left[\mathrm{M}+\mathrm{CH}_{3} \mathrm{COO}\right]^{-}$was chosen as the precursor ion.

Separation of the analytes was performed using a reversedphase BEH C18 column $(100 \times 2.1 \mathrm{~mm}, 1.7 \mu \mathrm{m})$. For the analyses performed in positive mode, the compounds were separated using $4 \mathrm{mM}$ ammonium formate buffer ( $\mathrm{pH} 3.4$ ) employed as mobile phase $A$ and acetonitrile as mobile phase $B$ at a flow rate of $0.2 \mathrm{~mL} /$ min. The gradient elution was as follows: $0.5-4 \mathrm{~min}, 5-25 \%$ (B); 4.0-8.0 min, 25-32\% (B); 8.0-11.0 min, 32-60\% (B); 11.0-18.5 min, $60-100 \%$ (B). The total analysis time was $20 \mathrm{~min}$. For tetracyclines performed in positive mode, compounds were separated using $0.1 \%$ formic acid employed as moblile phase $\mathrm{A}$ and acetonitrile as mobile phase $B$ at a flow rate of $0.25 \mathrm{~mL} / \mathrm{min}$. The gradient conditions were: $0.5-3.5 \mathrm{~min}, 10-30 \%$ (B); $3.5-4.5 \mathrm{~min}, 30-40 \%$ (B); 4.5-7.5 min, 40-90\% (B); 7.5-8.5 min, 90-100\% (B). The total analysis time was $10 \mathrm{~min}$. For analytes performed in negative mode, compounds were separated using $4 \mathrm{mM}$ ammonium acetate buffer ( $\mathrm{pH} 4.5$ ) as mobile phase $\mathrm{A}$ and acetonitrile as mobile phase $B$ at a flow rate of $0.25 \mathrm{~mL} / \mathrm{min}$. The gradient conditions were: $0.5-$ $4.5 \mathrm{~min}, 30-80 \%$ (B); 4.5-5.0 min, 80-100\% (B). The total analysis time was $6 \mathrm{~min}$. For estrogens performed in negative mode, compounds were separated using water as mobile phase A and acetonitrile as mobile phase $B$ at a flow rate of $0.25 \mathrm{~mL} / \mathrm{min}$. The gradient conditions were: $0.0-4.0 \mathrm{~min}, 40-50 \%$ (B); $4.0-4.5 \mathrm{~min}$, 50-100\% (B). The total analysis time was $6 \mathrm{~min}$.

\subsection{Quality control}

Linear calibration curves were constructed by analyzing standard solutions ranging from $0.01 \mu \mathrm{g} / \mathrm{L}$ to $100 \mu \mathrm{g} / \mathrm{L}$, covering four orders of magnitude. External quantification was performed using the Quanlynx software. One field blank and two laboratory blanks were analyzed for the targets during the course of this study. Analyses of the laboratory blanks demonstrated that the analytical procedure and glassware were free of contamination, and carbamazepine $(0.01 \mathrm{ng} / \mathrm{L})$ and DEET $(0.1 \mathrm{ng} / \mathrm{L})$ were detected in the 
field blank at negligible concentrations. The MDLs and method quantification limits (MQLs) for each target were listed in Table S4. However, it should be noted that the MDLs and MQLs are not constant values because of the performance of the variations of the instrument and blank contamination. In the recovery studies, three replicate samples were analyzed. They were performed by spiking ultrapure water with a mixture of native compounds at low ng/L level (Table S4).

\subsection{Statistical tests}

The concentrations of pharmaceuticals were analyzed by their maximum concentrations, 90th percentiles, and median concentrations. Non-parametric statistical techniques were employed to investigate the differences in both concentrations and detection frequencies. The Wilcoxon matched-pair signed-rank test was performed to test for seasonal differences. These two methods are appropriate because the concentration data of the pharmaceuticals were not normally distributed.

\section{Results}

\subsection{Frequency of detection}

Of the 135 targets analyzed, 70 were detected at least one sample. The 32 compounds with detection frequencies higher than $20 \%$ were listed in Table 1 . Of these 32 compounds, 14 were found

Table 1

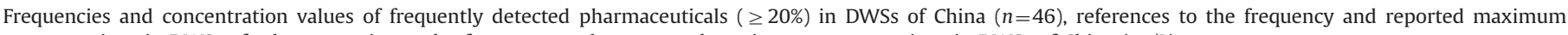
concentrations in DWSs of other countries, and references to other reported maximum concentrations in DWSs of China (ng/L).

\begin{tabular}{|c|c|c|c|c|c|c|c|}
\hline \multirow[t]{2}{*}{ Compound } & \multirow[t]{2}{*}{ Frequency } & \multirow{2}{*}{$\begin{array}{l}\text { Frequency in DWSs of } \\
\text { other countries }\end{array}$} & \multicolumn{5}{|c|}{ Concentration (ng/L) } \\
\hline & & & Max & $\begin{array}{l}90^{\text {th }} \\
\text { percentile }\end{array}$ & Median & Reported maximum in DWSs of other countries & $\begin{array}{l}\text { Reported } \\
\text { maximum in } \\
\text { DWSs of } \\
\text { China }\end{array}$ \\
\hline \multicolumn{8}{|c|}{ Compounds with recovery values from $60 \%$ to $140 \%$} \\
\hline Paraxanthine & $63 \%$ & $23 \%^{\mathrm{b}}, 82 \%^{\mathrm{j}}, 0 \%^{\mathrm{c}}$ & 116.0 & 59.7 & 16.5 & $300^{\mathrm{b}}, \sim 180^{\mathrm{j}}$ & \\
\hline Roxithromycin & $93 \%$ & $0 \%^{\mathrm{b}}, 0 \%^{\mathrm{c}}, 2 \%^{\mathrm{d}}$ & 27.4 & 3.6 & 0.9 & $66^{\mathrm{d}}, 4.1^{\mathrm{e}}$ & $39^{\circ}, 0.6^{\mathrm{p}}$ \\
\hline Carbamazepine & $100 \%$ & $21.6 \%^{\mathrm{b}}, 50 \%^{\mathrm{d}}, 92 \%^{\mathrm{c}}, 100 \%^{\mathrm{k}}$ & 3.5 & 1.6 & 0.2 & $121^{\mathrm{a}}, 190^{\mathrm{b}}, 600^{\mathrm{c}} 749^{\mathrm{d}}, 41.6^{\mathrm{e}}, 17.9^{\mathrm{g}}, 51^{\mathrm{h}}, 4.8^{\mathrm{i}},, 54^{\mathrm{k}}, 10^{\mathrm{l}}, 4.1^{\mathrm{n}}$ & $0.41^{\mathrm{p}}$ \\
\hline Diethyltoluamide (DEET) & $100 \%$ & $92 \%^{\mathrm{c}}, 32 \%^{\mathrm{h}}, 8 \%^{\mathrm{m}}$ & 10.2 & 7.3 & 3.4 & $110^{\mathrm{h}}, 2.0^{\mathrm{i}}, 131^{\mathrm{m}}, 255.7^{\mathrm{n}}$ & \\
\hline Lincomycin & $85 \%$ & $0 \%{ }^{\mathrm{b}}, 19 \%^{\mathrm{d}}, 17 \%{ }^{\mathrm{c}}$ & 57.2 & 31.5 & 7.5 & $143^{\mathrm{d}}, 17.9^{\mathrm{f}}, \sim 60^{\mathrm{c}}$ & $23^{\circ}$ \\
\hline Clarithromycin & $85 \%$ & & 21.0 & 1.4 & 0.6 & $54.4^{\mathrm{f}}, 1.7^{\mathrm{n}}$ & \\
\hline Cotinine & $76 \%$ & $35.1 \%^{b}, 92 \%^{c}$ & 88.5 & 42.3 & 11.9 & $100^{\mathrm{b}}, 37.2^{\mathrm{f}}, 29^{\mathrm{l}}, 10^{\mathrm{c}}, 2.7^{\mathrm{n}}$ & \\
\hline Metoprolol & $52 \%$ & $30 \%^{\mathrm{a}}, 58 \% \mathrm{k}$ & 0.6 & 0.3 & 0.1 & $107^{\mathrm{a}}, 0.8^{\mathrm{e}}, 380^{\mathrm{k}}, 0.1^{\mathrm{n}}$ & $0.53^{p}$ \\
\hline Diphenhydramine & $43 \%$ & $5.4 \%^{\mathrm{b}}, 0 \%$ & 0.1 & 0.1 & 0.05 & $23^{\mathrm{b}}$ & \\
\hline Benzene sulfonamide & $39 \%$ & & 1.3 & 0.7 & 0.2 & & \\
\hline Venlafaxine & $35 \%$ & $30 \%, 42 \%{ }^{\mathrm{k}}$ & 0.1 & 0.1 & 0.02 & $59^{\mathrm{a}}, 59^{\mathrm{k}}$ & \\
\hline Nalidixic acid & $22 \%$ & & 0.8 & 0.4 & 0.1 & & \\
\hline Androstenedione & $20 \%$ & & 0.6 & 0.6 & 0.3 & $2.1^{\mathrm{e}},<1.0^{\mathrm{i}}$ & \\
\hline Chloramphenicol & $20 \%$ & $0 \%{ }^{\mathrm{d}}$ & 1.3 & 1.2 & 0.6 & & \\
\hline \multicolumn{8}{|c|}{ Compounds with recovery values less than $60 \%$} \\
\hline Sulfamonomethoxine & $70 \%$ & & Detected & Detected & Detected & & \\
\hline Erythromycin dehydrate & $100 \%$ & $8.1 \%^{\mathrm{b}}, 58 \%^{\mathrm{c}}$ & Detected & Detected & Detected & $35^{\mathrm{a}}, 300^{\mathrm{b}}, 10^{\mathrm{c}}, 2.7^{\mathrm{n}}$ & $85^{\circ}, 1.41^{\mathrm{p}}$ \\
\hline Trimethoprim & $67 \%$ & $6.8 \%^{\mathrm{b}}, 0 \%^{\mathrm{c}}, 10 \%^{\mathrm{d}}, 58 \%{ }^{\mathrm{h}}$ & Detected & Detected & Detected & $25^{\mathrm{d}}, 0.2^{\mathrm{e}}, 11^{\mathrm{h}}, 22.8^{\mathrm{f}}, 20^{\mathrm{b}}, 10.9^{\mathrm{n}}$ & $8^{\circ}, 0.4^{\mathrm{P}}$ \\
\hline Sulfamethoxazole & $63 \%$ & $2.7 \%^{\mathrm{b}}, 18 \%^{\mathrm{d}}, 83 \%^{\mathrm{c}}, 89 \%^{\mathrm{h}}$ & Detected & Detected & Detected & $284^{\mathrm{d}}, 5.1^{\mathrm{e}}, 110^{\mathrm{h}}, 149^{\mathrm{f}}, 6^{\mathrm{l}}, 60^{\mathrm{c}}, 7.4^{\mathrm{n}}$ & $23^{\mathrm{o}}, 0.44^{\mathrm{p}}$ \\
\hline Sulfamethazine & $57 \%$ & $0 \%, 10 \%{ }^{\mathrm{d}}, 17 \%$ & Detected & Detected & Detected & $34^{\mathrm{d}}, 113^{\mathrm{f}}, 40^{\mathrm{c}}$ & $10^{\circ}, 0.4^{\mathrm{p}}$ \\
\hline Sulfadiazine & $50 \%$ & $0 \%^{\mathrm{c}}, 0 \%^{\mathrm{d}}$ & Detected & Detected & Detected & & $<5^{\circ}, 0.4^{p}$ \\
\hline Ibuprofen & $43 \%$ & $1.4 \%^{\mathrm{b}}, 21 \%^{\mathrm{d}}, 0 \%^{\mathrm{c}}, 8 \%^{\mathrm{m}}$ & Detected & Detected & Detected & $79^{\mathrm{d}}, 6.6^{\mathrm{e}}, 15^{\mathrm{i}}, 230^{\mathrm{f}}, 270^{\mathrm{b}}, 5850^{\mathrm{m}}, 132.9^{\mathrm{n}}$ & $1.34^{\mathrm{p}}$ \\
\hline Cimetidine & $41 \%$ & $0 \%^{\mathrm{b}}, 0 \%^{\mathrm{c}}$ & Detected & Detected & Detected & & \\
\hline Azithromycin & $41 \%$ & $1.4 \%^{\mathrm{b}}$ & Detected & Detected & Detected & $29^{\mathrm{b}}, 17.6^{\mathrm{f}}$ & $21.81^{\mathrm{p}}$ \\
\hline Thiabendazole & $37 \%$ & $0 \%{ }^{\mathrm{c}}$ & Detected & Detected & Detected & & \\
\hline Ofloxacin & $35 \%$ & $0 \%{ }^{\mathrm{c}}$ & Detected & Detected & Detected & & $74^{\circ}, 4.06^{\mathrm{P}}$ \\
\hline Naproxen & $35 \%$ & $21 \%^{\mathrm{d}}, 58 \%{ }^{\mathrm{h}}$ & Detected & Detected & Detected & $199^{\mathrm{d}}, 3.1^{\mathrm{e}}, 32^{\mathrm{h}}, 152^{\mathrm{f}}, 9.2^{\mathrm{n}}$ & \\
\hline Sulfaquinoxaline & $33 \%$ & & Detected & Detected & Detected & & \\
\hline Triclocarban & $33 \%$ & & Detected & Detected & Detected & & \\
\hline Acetaminophen & $30 \%$ & $8.1 \%^{\mathrm{b}}, 11 \%^{\mathrm{d}}, 75 \%^{\mathrm{c}}$ & Detected & Detected & Detected & $160^{\mathrm{b}}, 120^{\mathrm{c}}, 298^{\mathrm{d}}, 1.9^{\mathrm{e}}, 260^{\mathrm{f}}, 19.2^{\mathrm{n}}$ & $0.5^{\mathrm{p}}$ \\
\hline Sulfapyridine & $28 \%$ & & Detected & Detected & Detected & & \\
\hline Sulfachloropyridazine & $26 \%$ & $0 \%{ }^{\mathrm{c}}, 0 \%^{\mathrm{d}}$ & Detected & Detected & Detected & & \\
\hline Triclosan & $24 \%$ & $32 \%^{\mathrm{h}}, 0 \%^{\mathrm{c}}, 8 \%^{\mathrm{m}}$ & Detected & Detected & Detected & $6.4^{\mathrm{h}}, 734^{\mathrm{m}}, 105.8^{\mathrm{n}}$ & \\
\hline
\end{tabular}

a Netherlands (de Jongh et al., 2012).

b U.S. (Focazio et al., 2008).

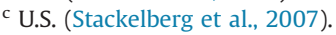

d Canada (Kleywegt et al., 2011).

e France (Vulliet et al., 2011).

${ }^{\mathrm{f}}$ Spain (Boleda et al., 2011).

g U.S. (Wang et al., 2011).

${ }^{\text {h }}$ U.S. (Benotti et al., 2009).

i South Korea (Kim et al., 2007).

j France (Mompelat et al., 2011).

k Spain (Huerta-Fontela et al., 2011).

${ }^{1}$ Spain (Valcárcel et al., 2013).

${ }^{\mathrm{m}}$ U.S. (Loraine and Pettigrove, 2005).

${ }^{\mathrm{n}}$ U.S. (Padhye et al., 2014).

${ }^{\circ}$ Five DWSs in the Yangtze River and its tributary, the Jialing River, Chongqing Area (Chang et al., 2010).

p Two DWSs in the Yangtze River and its tributary, the Jialing River, Chongqing Area (Yan et al., 2014). 
in the majority of samples ( $\geq 50 \%$ ). Among these, six were detected with detection frequencies higher than $80 \%$. Compounds with detection frequencies less than $20 \%$ or compounds not detected in any of the samples were listed in Table S5.

The six most frequently detected compounds ( $\geq 80 \%$ ) were carbamazepine (100\%, antiepileptic), DEET (100\%, insect repellent), erythromycin anhydrate (100\%, macrolide), roxithromycin (93\%, macrolide), lincomycin (85\%, lincosamide), and clarithromycin (85\%, macrolide). A nicotine metabolite (cotinine), a caffeine metabolite (paraxanthine), sulfonamides (sulfamonomethoxine, sulfamethoxazole, sulfamethazine, sulfadiazine), a $\beta$-blocker (metoprolol), and an antibiotic (trimethoprim) were also frequently detected (50\%-80\%). A serotonin re-uptake inhibitor (venlafaxine), NSAIDs (acetaminophen, ibuprofen and naproxen), quinolones (ofloxacin and nalidixic acid), sulfonamides (sulfaquinoxaline, sulfapyridine and sulfachloropyridazine) and a transformation product (benzene sulfonamide), chloramphenicol, an antihistamine (diphenhydramine), an antiulcer agent (cimetidine), a macrolide (azithromycin), an androgen (androstenedione), an antifungal (thiabendazole) and two antimicrobials (triclocarban and triclosan) were detected less frequently (20-50\%).

Several other pharmaceuticals, including some sulfonamides, some quinolones, serotonin re-uptake inhibitors (fluoxetine and citalopram), an anti-asthma drug (salbutamol), tranquilizers (prazepam and amisulpride), a lipid-regulating agent (gemfibrozil), a calcium channel blocker (diltiazem), some progestogens, some androgens, some corticoids and some estrogens were rarely detected $(<20 \%)$. All of the tetracyclines, six sulfonamides, 10 quinolones, the majority of the hormones (progestogens, androgens, corticoids and estrogens), spiramycin, ketoprofen, atenolol, lamotrigine and digoxigenin were not detected in any of the samples (Table S5).

\subsection{Concentration levels}

Table 1 shows the concentrations (maximum, $90^{\text {th }}$ percentile, and median values) of the most frequently detected pharmaceuticals ( $\geq 20 \%$ ). The concentrations varied across a range from sub ng/L concentrations to tens of ng/L, which were generally comparable to the reported levels from other published references concerned with DWSs of The Netherlands (de Jongh et al., 2012), United States (Loraine and Pettigrove, 2005; Stackelberg et al., 2007; Focazio et al., 2008; Benotti et al., 2009; Wang et al., 2011; Padhye et al., 2014), Canada (Kleywegt et al., 2011), France (Vulliet et al., 2011; Mompelat et al., 2011), Spain (Boleda et al., 2011; Huerta-Fontela et al., 2011) and South Korea (Kim et al., 2007). The concentration levels in this survey were similar to reports on those in the DWSs of the Chongqing area of China (Chang et al., 2010; Yan et al., 2014). They were also comparable to the reporting levels of surface water in China (Bu et al., 2013; Liu and Wong, 2013). The maximum concentration of paraxanthine exceeded $100 \mathrm{ng} / \mathrm{L}$. Five compounds, i.e., metoprolol, diphenhydramine, venlafaxine, nalidixic acid and androstenedione were detected at concentration levels of less than $1 \mathrm{ng} / \mathrm{L}$.

It is worth mentioning that the concentration levels of some analytes were approximate due to the low recovery values

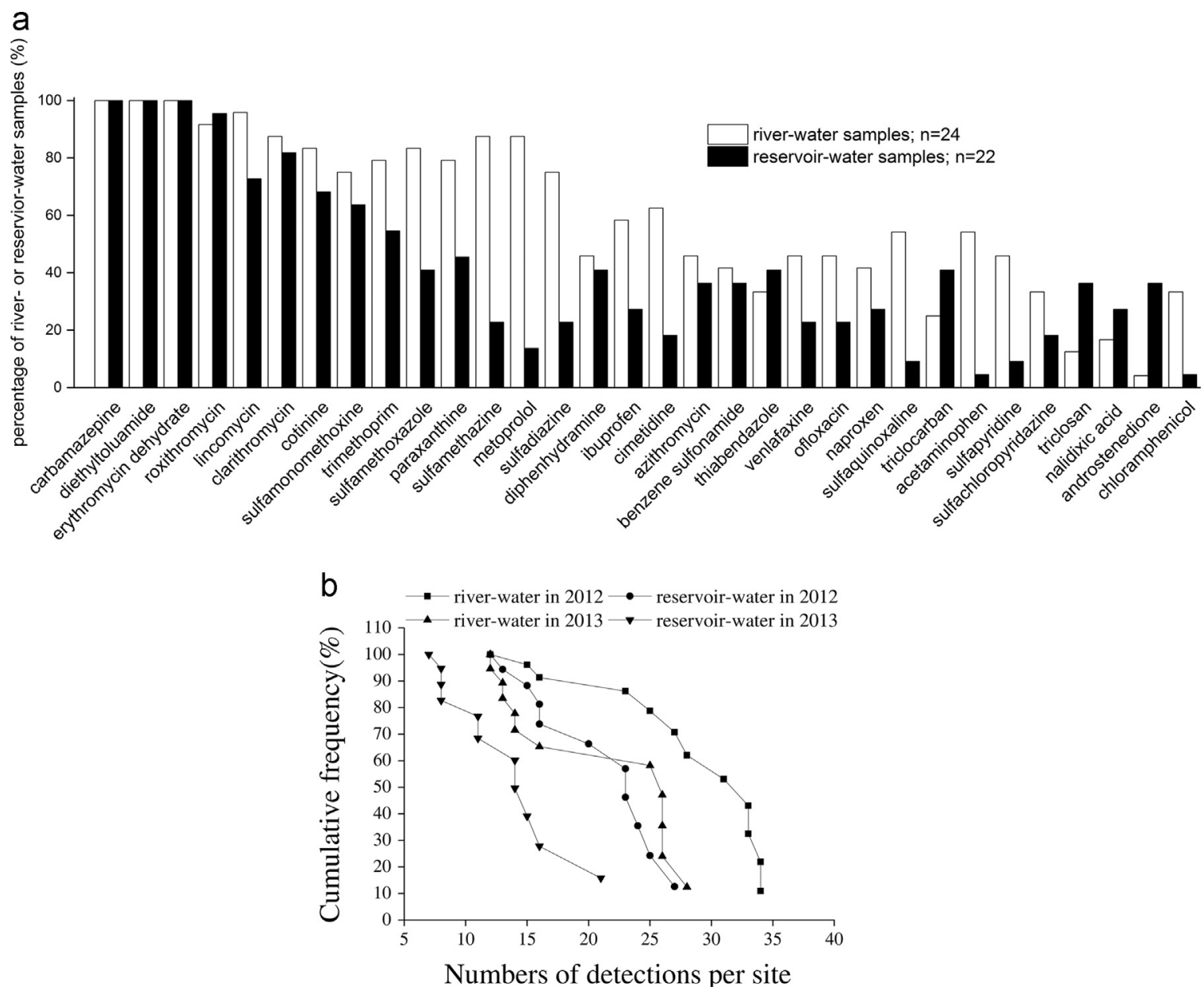

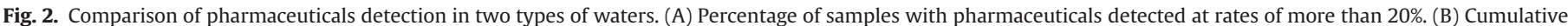
detection frequency of pharmaceuticals in each sample. 

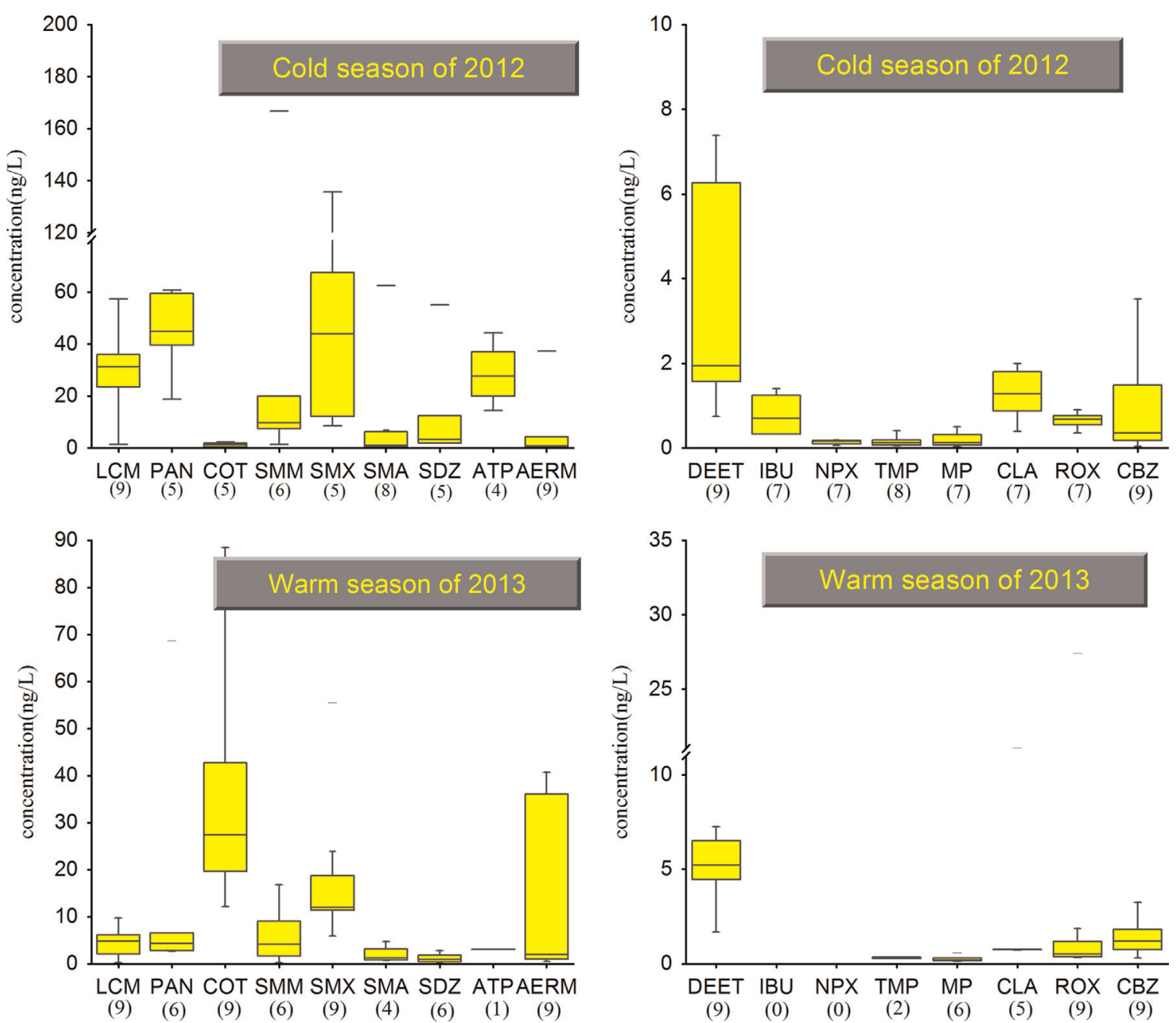

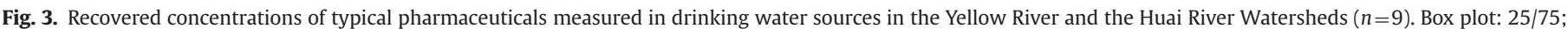

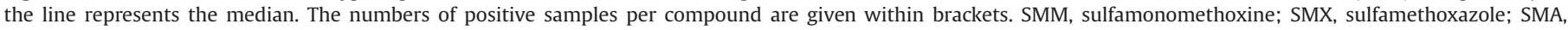

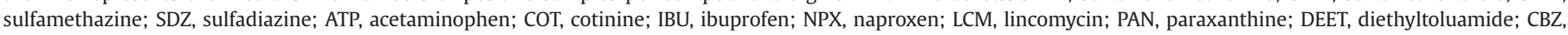
carbamazepine; TMP, trimethoprim; MP, metoprolol; AERM, erythromycin dehydrate; CLA, clarithromycin; ROX, roxithromycin.

(Table 1). Thus, the 32 most detected compounds ( $\geq 20 \%$ ) were divided into two groups: compounds with good recovery values and compounds with lower recovery values. The concentration levels for typical pharmaceuticals in 2012 and 2013 have been listed in Tables S6 and S7, respectively.

\subsection{Occurrence in river water and reservoir water}

Detection frequencies of pharmaceuticals were higher frequencies in river-type than in reservoir-type water samples, especially for caffeine metabolite paraxanthine, antiulcer agent cimetidine, $\beta$-blocker metoprolol, sulfonamides and NSAIDs (Fig. 2). Geographically, fewer categories and lower concentrations of sulfonamides were detected in the Liao River watershed (S20S25, Northern China, data not shown) than in the other four watersheds, most likely because of the forested surroundings of the sampling sites (Fig. 1). These sites were rarely affected by human activities.

\subsection{Seasonal variations in the Huai river and Yellow river watersheds}

Most of the sampling sites in the Huai River and Yellow River Watersheds (Sites S6-S14) were affected mainly by residential or agricultural activities. The seasonal variation was compared for the two successive sampling campaigns conducted during the cold season of 2012 and warm season of 2013, respectively (Fig. 3). In both river watersheds, no significant differences were found for most detected pharmaceuticals, including carbamazepine (Wilcoxon matched-pairs signed-rank test, $p=0.214$ ), DEET (Wilcoxon matched-pairs signed-rank test, $p=0.173$ ), and roxithromycin (Wilcoxon matched-pairs signed-rank test, $p=0.441$ ). However, the differences between the cold season and warm season samples were significant for a few pharmaceuticals, i.e., cotinine, lincomycin and several NSAIDs. The concentrations of cotinine were higher during the warm season than during the cold season (Wilcoxon matched-pairs signed-rank test, $p=0.008$ ), whereas the concentration of lincomycin was substantially lower during the warm season than during the cold season (Wilcoxon matchedpairs signed-rank test, $p=0.008$ ). Three NSAIDs, i.e., ibuprofen, acetaminophen and naproxen, were detected during cold season but rarely during the warm season.

\section{Discussion}

\subsection{Detections of pharmaceuticals in DWSs}

In the present study, multiple-classes of pharmaceuticals were detectable in DWSs in China. The detected pharmaceuticals 
included antibiotics, an antiepileptic, serotonin re-uptake inhibitors, an antiulcer agent, a $\beta$-blocker, an antihistamine, an antiasthma drug, tranquilizers, a lipid-regulating agent, a calcium channel blocker and hormones. The types of pharmaceuticals found in DWSs in China are similar to those found in other countries, such as the U.S. (Benotti et al., 2009; Focazio et al., 2008; Wang et al., 2011), Canada (Kleywegt et al., 2011), Denmark (de Jongh et al., 2012), Spain (Valcárcel et al., 2013), France (Mompelat et al., 2011; Vulliet et al., 2011) and South Korea (Kim et al., 2007).

The detection frequencies of pharmaceuticals were associated with the MDLs of analytical method employed. The MDLs of our method for pharmaceuticals, which included lincomycin, cotinine, paraxanthine, trimethoprim, cimetidine, diltiazem, ibuprofen, acetaminophen, chloramphenicol, erythromycin dehydrate, roxithromycin, azithromycin, carbamazepine, sulfamethoxazole, sulfamethazine, and sulfachloropyridazine $(0.006-0.6 \mathrm{ng} / \mathrm{L})$, were one or two orders of magnitude lower than those reported by previous studies (Cahill et al., 2004; Hao et al., 2008). Consequently, we observed higher frequencies of detection. Among these pharmaceuticals, the frequencies of detection for typical pharmaceuticals, such as lincomycin and roxithromycin (Table 1), were substantially higher than those reported for DWSs in the U.S. (Focazio et al., 2008) and Canada (Kleywegt et al., 2011). In this study, the maximum concentration of cimetidine measured in this study was $3.1 \mathrm{ng} / \mathrm{L}$ (with a MDL of $0.01 \mathrm{ng} / \mathrm{L}$ ), but cimetidine was rarely detected in a nationwide survey of DWSs in the U.S. (Focazio et al., 2008) that employed an analytical method (Cahill et al., 2004) with a MDL of $6.7 \mathrm{ng} / \mathrm{L}$. Similarly, the detection frequency of lincomycin with a MDL of $0.006 \mathrm{ng} / \mathrm{L}$, was $85 \%$ in this study, but lincomycin was not detected in DWSs in the U.S. (Focazio et al., 2008) and was rarely detected (19\%) in Canada (Kleywegt et al., 2011), the latter of which employed an analytical method (Hao et al., 2008) with MDL of $2.7 \mathrm{ng} / \mathrm{L}$.

The detection frequencies for four macrolides were substantially higher in this study (41-100\%) than those for other countries (de Jongh et al., 2012; Focazio et al., 2008; Kleywegt et al., 2011; Stackelberg et al., 2007; Vulliet et al., 2011), which might be related to their higher production volumes in China (Fig. 4). Three sulfonamides, i.e., sulfamonomethoxine, sulfadiazine and sulfachloropyridazine, were detected more frequently (Table 1 ) because they are widely used in veterinary medicine in China (Jia et al., 2011; Luo et al., 2011). Sulfamethoxazole and sulfamethazine were also frequently detected (57-63\%), corresponding to their relatively higher production volumes ( $2410 \mathrm{t}$ and $1451 \mathrm{t}$ in 2003, respectively) (Fig. 4). Similiarly, caffeine and nicotine were found to be ubiquitous in surface (Tagus River) and tap water in Central Spain, and the authors attributed the result to large consumptions of tobacco, coffee and tea (Valcárcel et al., 2013). In conclusion, variations in detection frequencies could be associated with the usage of pharmaceuticals in different countries.

Variations in detection frequencies may also be attributed to the ad/desorption processes of pharmaceuticals when discharged into aquatic environments. Two sub-groups of antibiotics, namely quinolones and tetracyclines, were rarely detected in this survey (Table S5), even though their domestic production volumes were relatively high (Fig. 4). They were also previously observed, but rarely detected in DWSs of the U.S. (Focazio et al., 2008; Stackelberg et al., 2007) and Canada (Kleywegt et al., 2011). This observation might be explained by their stronger adsorption capacities to particles, soils and sediments (Zhou et al., 2011), or by their strong interactions with natural organic matter (MacKay and Seremet, 2008) and metal oxides (Gu and Karthikeyan, 2005; Song et al., 2010).

Although the concentrations in the present survey were 0.8 $10.2 \mathrm{ng} / \mathrm{L}$ for DEET and 0.01-3.5 ng/L for carbamazepine, clearly lower than those previously reported (Focazio et al., 2008; Kleywegt et al., 2011), they were found in $100 \%$ of the samples. The ubiquitous detection of the antiepileptic carbamazepine and the insect repellant DEET may be explained by their resistance to natural degradation. These two compounds are resistant to the natural degradation process and are persistent in both distribution waters and tap waters (Benotti et al., 2009; Kleywegt et al., 2011; Mompelat et al., 2009). Therefore, they should be included in the

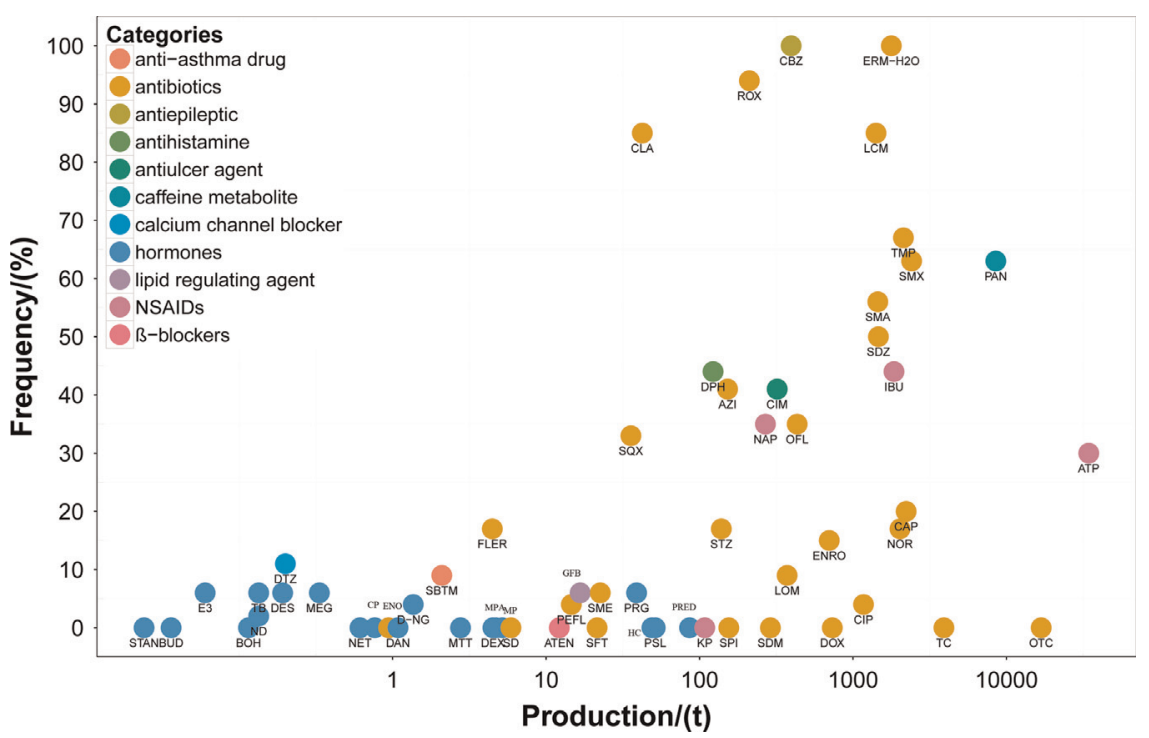

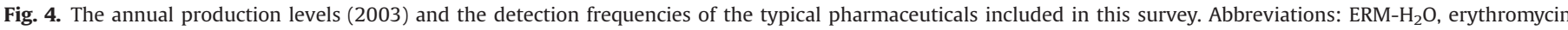

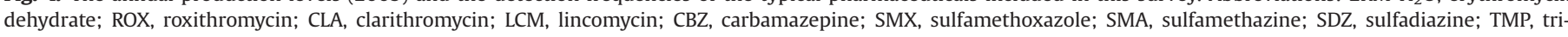

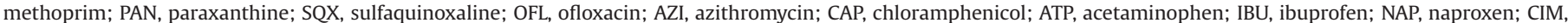

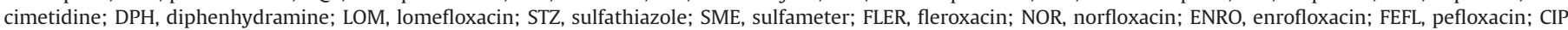

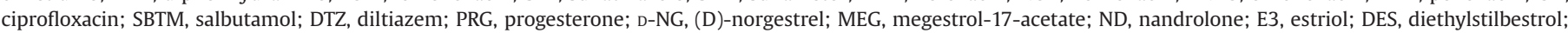

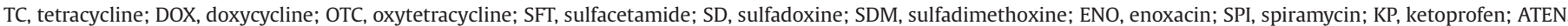

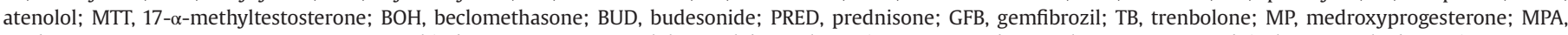

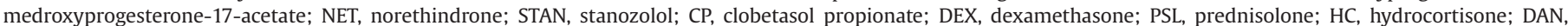
danazol. 
priority lists because of their persistence and potential health risks (Costanzo et al., 2007; Hampel et al., 2014).

Hormones, including progestogens, androgens, estrogens and corticoids, were rarely detected in this study. The lower detection frequencies of hormones might be attributed to their relatively lower discharge volumes in the surroundings of DWSs and degradation (Fig. 4). Another explanation was the detection limits of the employed analytical method. Estrone was found at $0.3-0.9 \mathrm{ng} /$ $\mathrm{L}$ in DWSs of the U.S., lower than $1 \mathrm{ng} / \mathrm{L}$ (Benotti et al., 2009). The MDL of estrone was $0.8 \mathrm{ng} / \mathrm{L}$ in this study. This probably was one of the reasons why estrone was not detected in this survey.

\subsection{Seasonal variations}

Several mechanisms had been proposed to explain seasonal variations in pharmaceuticals, including seasonal discharges, water temperature, irradiance and dilution effects (Daneshvar et al., 2010; Padhye et al., 2014). The lower temperatures presented during cold seasons result in slower rates of biodegradation than during the warm season. Decreased solar irradiation levels in autumn may reduce the photo-degradation rates of pharmaceuticals.

Higher concentrations of NSAIDs during cold seasons than during the warm season were also reported in Finland (Vieno et al., 2005). This agreed with a previous study of the Yellow River of China (Wang et al., 2010), where concentrations of NSAIDs were higher during the cold season (November and December) than during the warm season (May and July). Similarly, the concentrations of lincomycin were higher during the cold season (October and November) than during the warm season (July), which agreed with those reported in the raw water of DWTPs across Missouri (Wang et al., 2011). The consumption of antibiotics was much greater during winter than during the other seasons (Sun et al., 2012), which may result in higher inputs to water systems.

Higher concentrations of cotinine were observed during the warm season than during the cold season in both river basins. In the aquatic environment, cotinine accounted for the majority of nicotine metabolite (Martinez Bueno et al., 2011). The inter-season (summer, fall and winter) difference of cotinine was similar to those reported in four river samples of the Tagus River Basin, Spain (Valcárcel et al., 2013), and in an agricultural stream site (Buck Greek) in central Indiana, the U.S. (Veach and Bernot, 2011). One of the possible reasons might be the more rapid degradation of nicotine in warmer summer temperatures.

Carbamazepine showed no seasonal variation in this study, which is consistent with those observed in the Tagus River Basin, Spain (Valcárcel et al., 2013), where the flow rate remains relatively constant throughout the year. Carbamazepine is resistant to both hydrolysis and biodegradation in an aquatic environment (Lam et al., 2004).

A year-long study in the U.S. (Padhye et al., 2014) found out that peak concentrations of DEET were observed in early spring and in late summer because of less rainfall in spring and greater use during the summer. No seasonal variation (summer, fall and winter) for concentrations of DEET were observed in this survey.

\section{Conclusions}

This survey provides new baseline knowledge on the concentrations of a wide range of pharmaceuticals for 25 DWS sampling sites in five representative river watersheds in China. The results confirm the ubiquitous occurrence of pharmaceuticals in DWSs in China. A greater number of pharmaceuticals were detected in this work because of the significantly reduced detection limits of the analytical method. The usage and discharge of pharmaceuticals, as reflected by the surroundings, and their environmental characteristics should be considered as important factors that influence the contamination levels of pharmaceuticals in different geographical areas and different types of DWSs. Seasonal variations were observed for certain pharmaceuticals, i.e., lincomycin, cotinine and NSAIDs, which may be related to the environmental conditions that influence their degradation and seasonal usage or discharge. Particular attention should be paid to persistent pharmaceuticals that exhibit high detection frequencies and high concentrations, such as DEET and carbamazepine.

\section{Conflict of interest}

The authors declare that they have no conflict of interest.

\section{Acknowledgments}

We would like to acknowledge our colleagues (Mr. Wang Hailiang, Mr. Chen Xichao and Mr. Xu Xiong) for their assistance in site selection, sampling and sample pretreatment. Ms. Xu Dandan helped with the drawing of Fig. 1. Mr. Huang Chao helped with the drawing of Fig. 4. This work was supported by the Ministry of Water Resources' Special Funds for Scientific Research on Public Causes (Grant no. 201201032), and National Natural Science Foundation of China (51290283 and 21377002).

\section{Appendix A. Supplementary Information}

Supplementary data associated with this article can be found in the online version at http://dx.doi.org/10.1016/j.ecoenv.2015.03. 032.

\section{References}

Benotti, M.J., Trenholm, R.A., Vanderford, B.J., Holady, J.C., Stanford, B.D., Snyder, S. A., 2009. Pharmaceuticals and endocrine disrupting compounds in U.S. drinking water. Environ. Sci. Technol. 43, 597-603.

Boleda, M.R., Galceran, M.T., Ventura, F., 2011. Behavior of pharmaceuticals and drugs of abuse in a drinking water treatment plant (DWTP) using combined conventional and ultrafiltration and reverse osmosis (UF/RO) treatments. Environ. Pollut. 159, 1584-1591.

Bu, Q., Wang, B., Huang, J., Deng, S., Yu, G., 2013. Pharmaceuticals and personal care products in the aquatic environment in China: a review. J. Hazard. Mater. 262, 189-211.

Chang, X., Meyer, T.M., Liu, X., Zhao, Q., Chen, H., Chen, J., Qiu, Z., Yang, L., Cao, J., Shu, W., 2010. Determination of antibiotics in sewage from hospitals, nursery and slaughter house, wastewater treatment plant and source water in Chongqing region of Three Gorge Reservoir in China. Environ. Pollut. 158, 1444-1450.

Cahill, J.D., Furlong, E.T., Burkhardt, M.R., Kolpin, D., Anderson, L.G., 2004. Determination of pharmaceutical compounds in surface-and ground-water samples by solid-phase extraction and high-performance liquid chromatographyelectrospray ionization mass spectrometry. J. Chromatogr. A 1041, 171-180.

Costanzo, S.D., Watkinson, A.J., Murby, E.J., Kolpin, D.W., Sandstrom, M.W., 2007. Is there a risk associated with the insect repellent DEET (N,N-diethyl-m-toluamide) commonly found in aquatic environments? Sci. Total Environ. 384, 214-220.

Daneshvar, A., Svanfelt, J., Kronberg, L., Prévost, M., Weyhenmeyer, G.A., 2010. Seasonal variations in the occurrence and fate of basic and neutral pharmaceuticals in a Swedish river-lake system. Chemosphere 80, 301-309.

Daughton, C.G., 2003. Cradle-to-cradle stewardship of drugs for minimizing their environmental disposition while promoting human health. I. Rationale for and avenues toward a green pharmacy. Environ. Health Perspect. 111, 757-785.

de Jongh, C.M., Kooij, P.J.F., de Voogt, P., ter Laak, T.L., 2012. Screening and human health risk assessment of pharmaceuticals and their transformation products in Dutch surface waters and drinking water. Sci. Total Environ. 427, 70-77.

Delgado, L.F., Charles, P., Glucina, K., Morlay, C., 2012. QSAR-like models: a potential tool for the selection of PhACs and EDCs for monitoring purposes in drinking water treatment systems - a review. Water Res. 46, 6196-6209.

Fent, K., Weston, A.A., Caminada, D., 2006. Ecotoxicology of human pharmaceuticals. Aquat. Toxicol. 76, 122-159. 
Focazio, M.J., Kolpin, D.W., Barnes, K.K., Furlong, E.T., Meyer, M.T., Zaugg, S.D., Barber, L.B., Thurman, M.E., 2008. A national reconnaissance for pharmaceuticals and other organic wastewater contaminants in the United States - II) untreated drinking water sources. Sci. Total Environ. 402, 201-216.

Gu, C., Karthikeyan, K.G., 2005. Sorption of the antimicrobial ciprofloxacin to aluminum and iron hydrous oxides. Environ. Sci. Technol. 39, 9166-9173.

Hampel, M., Bron, J.E., Taggart, J.B., Leaver, M.J., 2014. The antidepressant drug carbamazepine induces differential transcriptome expression in the brain of Atlantic salmon, Salmo salar. Aquat. Toxicol. 151, 114-123.

Hao, C., Zhao, X., Tabe, S., Yang, P., 2008. Optimization of a multiresidual method for the determiantion of waterborne emerging organic pollutants using solidphase extraction and liquid chromatography/tandem mass spectrometry and isotope dilution mass spectrometry. Environ. Sci. Technol. 42, 4068-4075.

Huerta-Fontela, M., Teresa Galceran, M., Ventura, F., 2011. Occurrence and removal of pharmaceuticals and hormones through drinking water treatment. Water Res. 45, 1432-1442.

Jia, A., Hu, J.Y., Wu, X.Q., Peng, H., Wu, S.M., Dong, Z.M., 2011. Occurrence and source apportionment of sulfonamides and their metabolites in Liaodong Bay and the adjacent Liao River basin, North China. Environ. Toxicol. Chem. 30, 1252-1260.

Kim, S.D., Cho, J., Kim, I.S., Vanderford, B.J., Snyder, S.A., 2007. Occurrence and removal of pharmaceuticals and endocrine disruptors in South Korean surface, drinking, and waste waters. Water Res. 41, 1013-1021.

Kleywegt, S., Pileggi, V., Yang, P., Hao, C., Zhao, X., Rocks, C., Thach, S., Cheung, P., Whitehead, B., 2011. Pharmaceuticals, hormones and bisphenol A in untreated source and finished drinking water in Ontario, Canada - occurrence and treatment efficiency. Sci. Total Environ. 409, 1481-1488.

Kolpin, D.W., Furlong, E.T., Meyer, M.T., Thurman, E.M., Zaugg, S.D., Barber, L.B. Buxton, H.T., 2002. Pharmaceuticals, hormones, and other organic wastewater contaminants in U.S. streams, 1999-2000: a national reconnaissance. Environ. Sci. Technol. 36, 1202-1211.

Kuch, H.M., Ballschmiter, K., 2001. Determination of endocrine-disrupting phenolic compounds and estrogens in surface and drinking water by HRGC $-(\mathrm{NCI})-\mathrm{MS}$ in the picogram per liter range. Environ. Sci. Technol. 35, 3201-3206.

Lam, M.W., Young, C.J., Brain, R.A., Johnson, D.J., Hanson, M.A., Wilson, C.J., Richards, S.M., Solomon, K.R., Mabury, S.A., 2004. Aquatic persistence of eight pharmaceuticals in a microcosm study. Environ. Toxicol. Chem. 23, 1431-1440.

Li, W., Shi, Y., Gao, L., Liu, J., Cai, Y., 2013. Occurrence, distribution and potential affecting factors of antibiotics in sewage sludge of wastewater treatment plants in China. Sci. Total Environ. 445-446, 306-313.

Liu, J.L., Wong, M.H., 2013. Pharmaceuticals and personal care products (PPCPs): a review on environmental contamination in China. Environ. Int. 59, 208-224.

Loraine, G.A., Pettigrove, M.E., 2005. Seasonal variations in concentrations of pharmaceuticals and personal care products in drinking water and reclaimed wastewater in Southern California. Environ. Sci. Technol. 40, 687-695.

Luo, Y., Xu, L., Rysz, M., Wang, Y., Zhang, H., Alvarez, P.J.J., 2011. Occurrence and transport of tetracycline, sulfonamide, quinolone, and macrolide antibiotics in the Haihe River Basin, China. Environ. Sci. Technol. 45, 1827-1833.

MacKay, A.A., Seremet, D.E., 2008. Probe compounds to quantify cation exchange and complexation interactions of ciprofloxacin with soils. Environ. Sci. Technol. $42,8270-8276$.

Martinez Bueno, M.J., Ucles, S., Hernando, M.D., Davoli, E., Fernandez-Alba, A.R., 2011. Evaluation of selected ubiquitous contaminants in the aquatic environment and their transformation products. A pilot study of their removal from a sewage treatment plant. Water Res. 45, 2331-2341.

Mompelat, S., Le Bot, B., Thomas, O., 2009. Occurrence and fate of pharmaceutical products and by-products, from resource to drinking water. Environ. Int. 35, 803-814.

Mompelat, S., Thomas, O., Le Bot, B., 2011. Contamination levels of human pharmaceutical compounds in French surface and drinking water. J. Environ. Monit. 13, 2929-2939.

Nikolaou, A., Meric, S., Fatta, D., 2007. Occurrence patterns of pharmaceuticals in water and wastewater environments. Anal. Bioanal. Chem. 387, 1225-1234.

Padhye, L.P., Yao, H., Kung'u, F.T., Huang, C.H., 2014. Year-long evaluation on the occurrence and fate of pharmaceuticals, personal care products, and endocrine disrupting chemicals in an urban drinking water treatment plant. Water Res. 51, 266-276.

Song, W., Ding, Y., Chiou, C.T., Li, H., 2010. Selected veterinary pharmaceuticals in agricultural water and soil from land application of animal manure. J. Environ. Qual. 39, 1211-1217.

Stackelberg, P.E., Furlong, E.T., Meyer, M.T., Zaugg, S.D., Henderson, A.K., Reissman, D.B., 2004. Persistence of pharmaceutical compounds and other organic wastewater contaminants in a conventional drinking-water-treatment plant. Sci. Total Environ. 329, 99-113.

Stackelberg, P.E., Gibs, J., Furlong, E.T., Meyer, M.T., Zaugg, S.D., Lippincott, R.L., 2007. Efficiency of conventional drinking-water-treatment processes in removal of pharmaceuticals and other organic compounds. Sci. Total Environ. 377, 255-272.

Sun, L., Klein., E.Y., Laxminarayan, R., 2012. Seasonality and temporal correlation between community antibiotic use and resistance in the United States. Clin. Infect. Dis. 55, 687-694.

Valcárcel, Y., Alonso, S.G., Rodríguez-Gil, J.L., Castaño, A., Montero, J.C., Criado-Alvarez, J.J., Mirón, I.J., Catalá, M., 2013. Seasonal variation of pharmaceutically active compounds in surface (Tagus River) and tap water (Central Spain). Environ. Sci. Pollut. Res. 20, 1396-1421.

Veach, A.M., Bernot, M.J., 2011. Temporal variation of pharmaceuticals in an urban and agriculturally influenced stream. Sci. Total Environ. 409, 4553-4563.

Vieno, N.M., Tuhkanen, T., Kronberg, L., 2005. Seasonal variation in the occurrence of pharmaceuticals in effluents from a sewage treatment plant and in the recipient water. Environ. Sci. Technol. 39, 8220-8226.

Vosges, M., Braguer, J.C., Combarnous, Y., 2008. Long-term exposure of male rats to low-dose ethinylestradiol (EE2) in drinking water: effects on ponderal growth and on litter size of their progeny. Reprod. Toxicol. 25, 161-168.

Vulliet, E., Cren-Olive, C., Grenier-Loustalot, M.-F., 2011. Occurrence of pharmaceuticals and hormones in drinking water treated from surface waters. Environ. Chem. Lett. 9, 103-144.

Wang, C., Shi, H., Adams, C.D., Gamagedara, S., Stayton, I., Timmons, T., Ma, Y., 2011 Investigation of pharmaceuticals in Missouri natural and drinking water using high performance liquid chromatography-tandem mass spectrometry. Water Res, 45, 1818-1828.

Wang, L., Ying, G.G., Zhao, J.L., Yang, X.B., Chen, F., Tao, R., Liu, S., Zhou, L.J., 2010. Occurrence and risk assessment of acidic pharmaceuticals in the Yellow River Hai River and Liao River of north China. Sci. Total. Environ. 408, 3139-3147.

Yan, Q., Zhang, Y., Kang, J., Gan, X., Peng, X., Guo, J., Gao, X., 2014. A preliminary study on the occurrence of pharmaceutically active compounds in the river basins and their removal in two conventional drinking water treatment plants in Chongqing, China. CLEAN-Soil, Air, Water 42, 1-10.

Zhou, L.J., Ying, G.G., Zhao, J.L., Yang, J.F., Wang, L., Yang, B., Liu, S., 2011. Trends in the occurrence of human and veterinary antibiotics in the sediments of the Yellow River, Hai River and Liao River in northern China. Environ. Pollut. 159, 1877-1885.

Zou, S., Xu, W., Zhang, R., Tang, J., Chen, Y., Zhang, G., 2011. Occurrence and distribution of antibiotics in coastal water of the Bohai Bay, China: impacts of river discharge and aquaculture activities. Environ. Pollut. 159, 2913-2920. 